Please do not remove this page

RMIT

UNIVERSITY

\title{
A study of project management leadership styles across life cycle stages of an IT project in Hong Kong
}

Ng, Chui; Walker, Derek

https://researchrepository.rmit.edu.au/esploro/outputs/9921861067001341/filesAndLinks?institution=61RMIT_INST\&index=null

$\mathrm{Ng}, \mathrm{C} .$, \& Walker, D. (2008). A study of project management leadership styles across life cycle stages of an IT project in Hong Kong. International Journal of Managing Projects in Business, 1(3), 404-427.

https://doi.org/10.1108/17538370810883846

Document Version: Accepted Manuscript

Published Version: https://doi.org/10.1108/17538370810883846

Repository homepage: https://researchrepository.rmit.edu.au

(c) Emerald Group Publishing Limited

Downloaded On 2023/04/26 20:32:30 +1000

Please do not remove this page 
$\mathrm{Ng}, \mathrm{C}$ and Walker, D 2008, 'A study of project management leadership styles across life cycle stages of an IT project in Hong Kong', International Journal of Managing Projects in Business, vol. 1, no. 3, pp. 404-427.

\title{
A Study of Project Management Leadership Styles Across Life Cycle Stages of an IT Project in Hong Kong
}

\author{
Chui-Ha (Tracy) Ng, RMIT University, Melbourne, Australia \\ Derek H.T. Walker, RMIT University, Melbourne, Australia \\ Email Derek.walker@rmit.edu.au
}

Paper submitted November 2007, accepted March 2008

\begin{abstract}
Purpose: This paper provides a discussion of the way that teams and leaders interact over the life cycle stages of a project and how trust and confidence plays a vital part in this intimate relationship. Key issues relevant to this discussion are the nature of projects, the nature of trust and commitment and leadership style.

Design/Methodology/Approach: A case study was undertaken of an information and communication technology (ICT) project delivered by an information technology (IT) company to a Hong Kong public sector organisation. The study extended over the whole of the project and data was gathered on how the leadership styles of individuals in 'leader' positions of a project affected project management process success and failure from a critical historical event perspective. The study was considered over 4 stages: project initiation and design; development; testing and cut over; and finally project acceptance.

Findings: This paper highlights personnel changes in the leadership team. Issues relating to the leadership team of the public sector organisation and IT company are then explored, analysed and discussed. The source and use of power from the perspective of project delivery team leaders and the public sector organisation are explored to analyse how the adopted leadership style influenced the degree of trust and commitment exhibited by participants at each stage.

Practical Implications: Results suggest that team members should be considered as key project stakeholders and building their trust and confidence in the project leadership group is vital. The paper also explores cultural national issues that affect leadership style that are particularly relevant in a Confucian cultural context. While findings from one study cannot be more generally applied they do help to build our understanding of processes at work and what critical incidents influence the way that these unfold-in this case the way that leadership style affected the organisational form for example. Originality: Each case study is unique. This study provides particularly rich insights into the project and its characteristics across each stage of the project and so it contributes to the body of casework that helps explain the implications of how history, culture and context shapes the emergence of a particular leadership and followership style.

Paper Type: Research paper with a case study Keywords: Project Management, Teams, Leadership, Culture, IT
\end{abstract}




\section{Introduction}

Project work is distinctly different from operational work. Projects are singular events even though they may constitute part of a coherent program of discrete projects. They use temporary management structures that are formed to undertake the project and are then disbanded (Lundin and Söderholm, 1995). Teams of individuals engaged in a project are more often than not specialists, fulfilling a specific role, entering the 'project team' when needed as leaving that team when they are no longer required (Turner and Müller, 2003). Further, teams are composed of a mixture of people with different accountability relationships to the project manager. Some may have a direct line accountability relationship to act directly upon instructions while others are contracted to provide a specialist service and therefore are required to fulfil a specified or implied need, often in a chaotic environment (Cicmil, 1999). This makes the task of managing the coordination of a project team very (technically) complex and leading a project team to inspire them to deliver the project benefit is a very difficult (people-management) task-particularly as the temporary nature of projects imposes a lack of certainty relating to transition relationships and therefore the complex interplay of power, influence, accountability and responsiveness (Lundin and Söderholm, 1995). So, project work imposes different constraints than the general management literature assumes on how leaders influence those who deliver project outcomes.

The paper is structured as follows. First we outline leadership concepts, the nature of project work (especially in terms of complex product and systems projects), power and commitment, we will next provide a brief description of the case study and how major events and historical influences affected the style of those leading the project. This is then followed by a discussion of findings. The paper finally concludes with some implications for professional practice.

\section{Theoretical Underpinning}

Who are the leaders of projects? One answer is the project manager, however the PMBOK® Guide (PMI, 2004: p25) indicates that the project manager lies at the centre of action by coordinating and managing the project team's activities with secondary and sometimes removed influence over (and being influenced by) a range of project stakeholders that are not project team members. Further, where a project uses outsourced entities to provide expertise, each of these entities will have a project manager within that entity to lead that particular group and to coordinate activities with the main project manager accountable for the whole project. Another important leadership role is the project sponsor (Helm and Remington, 2005) who champions the project and perhaps initiates the project (Kloppenborg, Tesch, Manolis and Heitkamp, 2006), is instrumental in gaining support for resources (Englund and Bucero, 2006), and may be the person (or group) that the project manager is accountable to and who in turn is accountable to the client or the client's board of directors (Crawford and CookeDavies, 2006).

Managing complex projects information and communication technology (ICT) and information technology (IT) projects that not only involve delivering systems but also reengineering management processes and customer interfaces requires a great deal of 
integration of the skills and input of a diverse range of specialised skills and technical resources as well as integration of equipment, technology and training and development of new skill sets to be used with the new 'system'. Also there is the issue of the overlap or difference between managing and leading. Kotter (1998: p104) states that management is about coping with complexity while leadership is about coping with change. However, in cases such as the one presented in this paper, the deliverable is both a product and service that radically changes the organisation acquiring the output of the project. It is one of the types of projects described as a complex product and systems project by Hobday (1998; Hobday, Rush and Tidd, 2000). In this project type the output/outcome is not only product delivery but also radical innovative change. One of the skills required of change project leaders is the ability to inspire meaning through articulating a clear and achievable vision of a project (Castka, Bamber, Sharp and Belohoubek, 2001; Lynn and Akgün, 2001; Christenson and Walker, 2004). This skill is one of several needed for transformational leadership (Avolio, Waldman and Yammarino, 1991; Avolio, Gardner, Walumbwa and May, 2004) and authentic leadership that integrates inspiration with integrity that engenders commitment in others to help deliver the vision. Another leadership skill that has been identified is a political skill in managing stakeholder engagement-what Bourne (2005) refer to as 'tapping into the power lines' (Bourne and Walker, 2004). The political acumen skill is vital in complex projects.

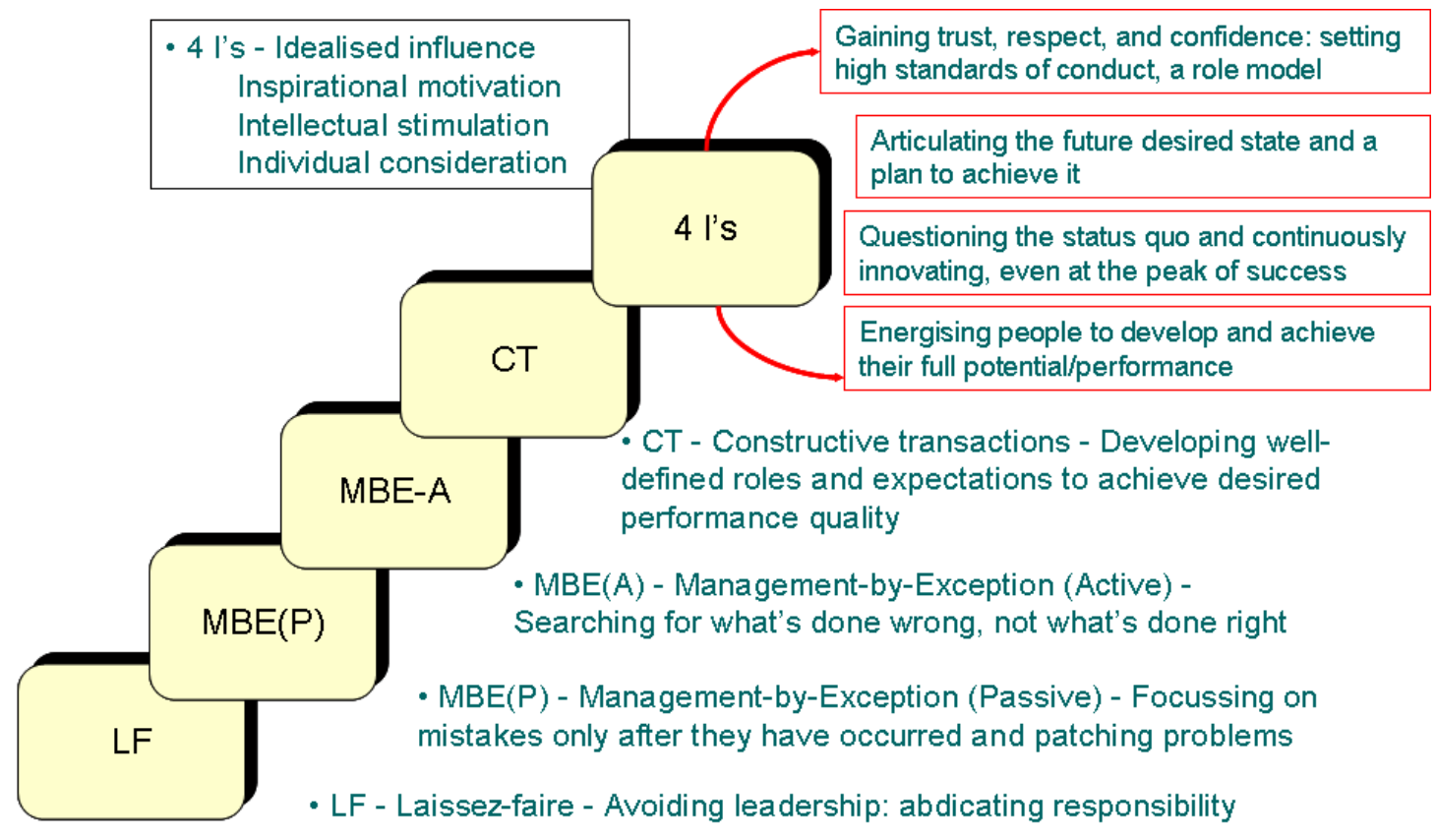

Figure 1 - A leadership style progression: Source (Avolio, 1996)

Avolio (1996: p5) illustrates leadership styles in Figure 1 as evolving in maturity of leaders and followers moving from a laissez-faire through passive and active management by exception through to constructive transactional then to transformational leadership that employs the four l's. These are idealised influence, inspirational motivation, intellectual inspiration and individual consideration. This trajectory is 
dependent upon the nature of the relationship between leaders and followers, similar to that proposed many years ago by Hersey, Blanchard and Johnson (1996) who claimed that this relationship determined the leadership styles of telling, selling, sharing ideas and coaching facilitating action or delegating full responsibility for planning and taking action.

Power and influence is not deployed in a cultural vacuum. The literature on national culture identifies a number of defining traits of people based on their national cultural upbringing (Hofstede, 1980; Hofstede, Neuijen, Ohayv and Sanders, 1990; Hofstede, 1991; Trompenaars, 1993; Trompenaars and Hampden-Turner, 2004). Some of the more salient aspects of the literature relating to the case study reported upon here is the influence of culture upon power and commitment in a Confucian cultural setting such as Hong Kong. Wang and Liu (2007) for example identify four cultural barriers to project management in mainland China: the Doctrine of the Mean, Strong Hierarchy, Family Consciousness, and Boss Orientation. They conducted an extensive study of a range of enterprises using a project management approach in Yunnan province and concluded that (Wang and Liu, 2007: p69):

o The Doctrine of the Mean (stressing avoidance of conflict by pushing disagreement under the surface) requires people to be less direct and less open, and encourages people to use compromising and smoothing strategies for dealing with conflict;

o A strong hierarchy requires large power distance between superior and subordinator;

o Family consciousness stresses long-term relationships, singularity of group, the central role of jiazhang ${ }^{1}$, and guanxi $i^{2}$-oriented evaluation of other people; and

o A boss orientation stresses the need to make the boss happy and evaluate people by their hierarchical position.

While the culture of Yunaan and mainland China in general has subtle but real differences with Hong Kong due to its Western historical influence, the underlying Confucian culture does exert a significant impact on the way that people react to authority. For example the 'home base' of the company (Western or Chinese family) would moderate this influence in Hong Kong and also the company 'feels' like a large dispassionate enterprise or a close family one. Further, in Hong Kong, issues are not generally raised publicly but rather privately. Finally, in Hong Kong performance is assessed more transparently with less stress on keeping the boss happy than suggested by Wang and Liu (2007: p69) findings.

The way that this can be realised is through the use of power to influence those in project teams to be committed. Meyer and Allen (1991) have identified three types of

\footnotetext{
${ }^{1}$ Jiazhang refers to leaders of the family however that 'family' may be conceived. Under jiazhangzhi, there is a top leader in any organization or any group of people to whom all other members must unconditionally obey.

${ }^{2}$ Guanxi refers to the personal relationships that determines behaviour and the way that obligations are discharged for a more extensive explanation see for example Park, S. H. and Luo, Y. (2001). "Guanxi and organizational dynamics: organizational networking in Chinese firms." Strategic Management Journal. 22 (5): 455-477.
} 
commitment; affective commitment, continuance, and normative. Affective commitment is an intrinsic desire to do something and represents a powerful influencing force. Continuance commitment is a transaction-based commitment because it involves calculating the relative value of the cost invested in being committed to the benefits to be derived from that commitment. Normative commitment is associated with duty. One could also include compliance in this continuum of being committed where compliance is about being required or forced to conform. Gaining commitment (of any of these types) is generally elicited through the influence of a leader or project manager.

There is much in the literature that relates to power and its sources for example see (Cartwright and Zander, 1960; Hersey et al., 1996; Yukl, 1998). Detailed discussion of this is beyond the scope of this paper. However three sources of power will be briefly outlined. Position power derives from statutory or formal organisational authority associated with an ability to control resources and rewards etc. Personal power relates to expertise, charisma, friendship or loyalty. Political power is derived from control of a decision process, participation in coalitions and being able to co-opt others in a common goal. Leaders and managers use power to influence team members and stakeholders engaged in a subtle interplay over sharing resources including information, as rewards and enticements to collaborate towards achieving a project's vision, mission and goals.

The way that power and influence can be applied by managers and leaders in realising project varies throughout project phases as the various players have varying degrees of innate power and this influences the various types of commitment. The value that this paper provides is that it uses a case study to illustrate how various types of power was used to influence team members across the identified project phases so that we can better understand the underlying dynamics at work.

In any sizable project, the leadership group (project managers and leaders) will deploy different leadership styles. In this paper an ICT project delivered by an IT company (coded as Vendor in this paper) to a public sector organisation (coded as Client in this paper) will be used to discuss how did the leadership styles of various individuals in 'leader' positions of the project through the project's delivery stages affect project success and failure. Project success has been the subject of much study (de Wit, 1988; Morris and Hough, 1993; Cooke-Davies, 2002; Kendra and Taplan, 2004), we will concentrate on project success as being perceived 'delivery of the promise' which not only concerns the iron triangle of time, cost and fitness for use but also some of the intangible factors such as participant's satisfaction in their involvement with the project.

\section{Research Approach}

The research approach for this case study is based on reflection by one of the authors who was a key senior person in the project that was deeply engaged in this project and totally immersed in the lived experience of the project. Notes and observations were maintained and later used to make sense of the situation using a process of reflection of the way that the project history unfolded and the forces and influences at work. This approach has strengths in that it taps into the rich data and appreciation of both 'facts' and emotions surrounding the case study. The weakness of the approach that is 
recognised and guarded against is that the approach is subject to bias and selfdelusion. This can in part be countered by eliciting feedback from participants to ensure that impressions have been reasonably and credibly interpreted. Winter and Thomas (2004) describe the value of understanding the lived experience of project team members engaged in project management (PM) work. They introduce their chapter by saying "Project managers often speak of their experiences of managing with a kind of natural affinity to jugglers and plate-spinners: so much time spent managing day-to-day issues, so much time spent trying to balance priorities in relation to unexpected events, changing requirements, and new developments. Yet the classical textbook view of project management tends not to reflect this. Traditional approaches to theorizing project management are dominated by assumptions privileging stability, linearity, routine, order, and control (Winter and Thomas, 2004: p419)". Their work and that of others, for example Cicmil (2006), Cicmil and Hodgson (2005), Green (2006) or Ivory, Alderman, Ian and Vaughan (2006: p320), explores the richness of knowledge that can be gained from being a reflective observer or indeed participant. This participative action research (PAR) approach has been argued to lead to deep insights about what is going on than can be derived from macro-scale surveys and other quantitative methods (McIntyre, 2002; Sense and Antoni, 2003; Sense, 2005; Lennie, 2006). This opens up a whole range of possibilities of research into PM topics.

The data was when grouped and made sense of through considering critical events during the project. This historical approach to case study work has been well established in the management field by using for example processual analysis (Pettigrew, 1997). This extends the concept of reflection on practice (Schön, 1983) by anchoring key events to actions that influenced changes in processes used. Pettigrew (1997: p339) argues that "the legacy of the past is always shaping the emerging future. What happens, how it happens, what results it brings about is dependent upon when it happens, the location in the processual sequence, the place in the rhythm of events ...". So it is appropriate to study the deep context and impact of key historical that trigger changes. In this case, the focus is upon cultural and project exigency influences upon power, influence and leadership style and how this shaped the way that a particular project's organizational structure changed over project phases.

\section{Project Case Study Context}

This project's objective was to replace and re-engineer a mainframe based, microfiche storage and look-up system with a network-based ICT system using imaging technologies that would allow internet access by the public to data previously available only by microfiche. The contract was awarded to the Vendor through open tender process. The project was undertaken in Hong Kong. It was a total solution project with the Vendor to supply all hardware, software, implementation and support services. The contract value was multi-million US dollars (approximately US\$4 million) and was targeted to be implemented in 18 months from project commencement.

The actual schedule, illustrated in Figure 2 summarising the tender and actual times, will be used to anchor events. The project took 30 months to complete from commencement to production and another 12 months to finalise a negotiated settlement 
(between the Client and Vendor) over the cost paid to the Vendor for delivering the final outcome. Many complex long-haul projects of this kind experience a high people turnover churn rate as an unavoidable consequence of a high-stress (Standish, 2003).

Tender Schedule

\begin{tabular}{|l|}
\hline $\begin{array}{l}\text { Stage 1: } \\
\text { Project initiation \& } \\
\text { design }\end{array}$ \\
\hline $\begin{array}{l}\text { Stage } 2: \\
\text { Development }\end{array}$ \\
\hline $\begin{array}{l}\text { Stage } 3 \text { : } \\
\text { Testing and } \\
\text { production cut over }\end{array}$ \\
\hline $\begin{array}{l}\text { Stage } 4: \\
\text { Project acceptance }\end{array}$ \\
\hline
\end{tabular}

Actual Schedule

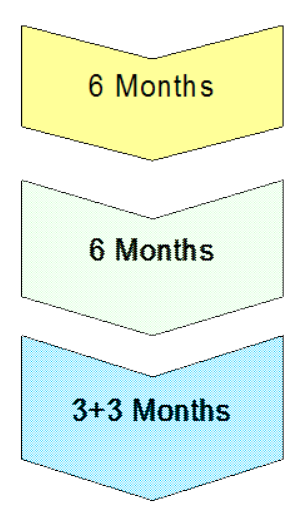

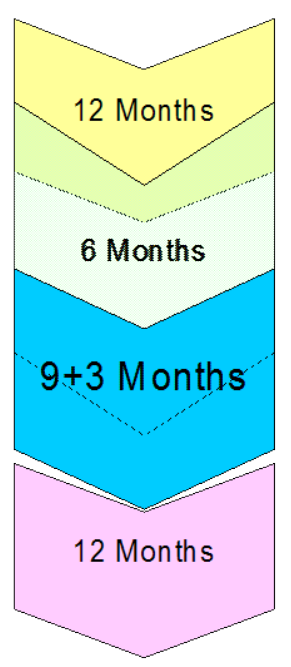

Figure 2 - Tender versus Actual Project Time Phase History

The churn rate, and reasons behind it, illustrates some of the issues faced by senior project leaders that provide contextual data to help understand the tensions that arose over the life cycle of this project. All this took place within the cultural context of interpersonality 'chemistry' with much of the 'storming' element being apparent as discussed in the 'forming, storming, norming and performing' (Tuckman and Jensen, 1977). 


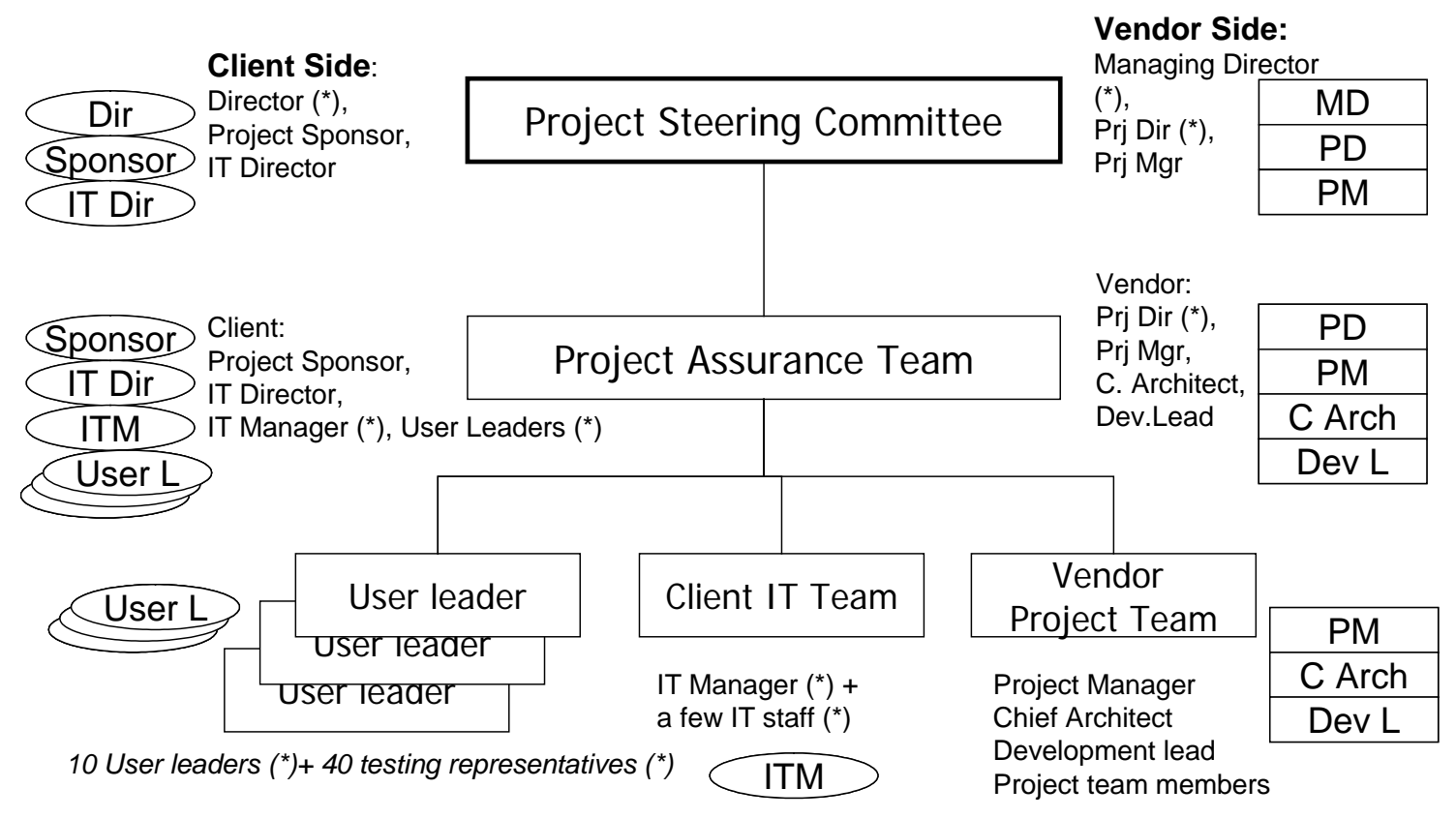

(*) Part-time participants on Project

Figure 3 - Project Organisation - Original Structure

Figure 3 illustrates the initial project team structure. It was composed of the following team roles. The Client side leadership team was composed of one project sponsor, one IT director, ten key user leaders and one IT manager. On the Vendor side the leadership team comprised one part-time project director, one project manager, one chief architect and one development lead. By the time the project was completed and handed over, the Client's leadership team remained relatively stable, a director and operation manager were the only addition to their team, and the IT manager was replaced by another candidate in the last stage of the project. On Vendor side, they added the managing director (head of the country) and a development manager to the leadership team, while making the project director to work almost full-time on the project. Throughout the project life-cycle, in total the Vendor had three managing directors, three project directors, four project managers, one development manager, one chief architect and one development lead in the leadership team at different period of time. The attrition of the project team level was low on both Client side and Vendor side.

The whole project is described as being divided into 4 stages. This paper highlights personnel changes in the leadership team and presents major events and problems in each stage. This allows analysis of issues relating to the leadership team of Client and Vendor, and their impact on the project success and failure.

The history of the project is presented as unfolding in four distinct stages and described as follows.

Stage 1: Project initiation and design stage 


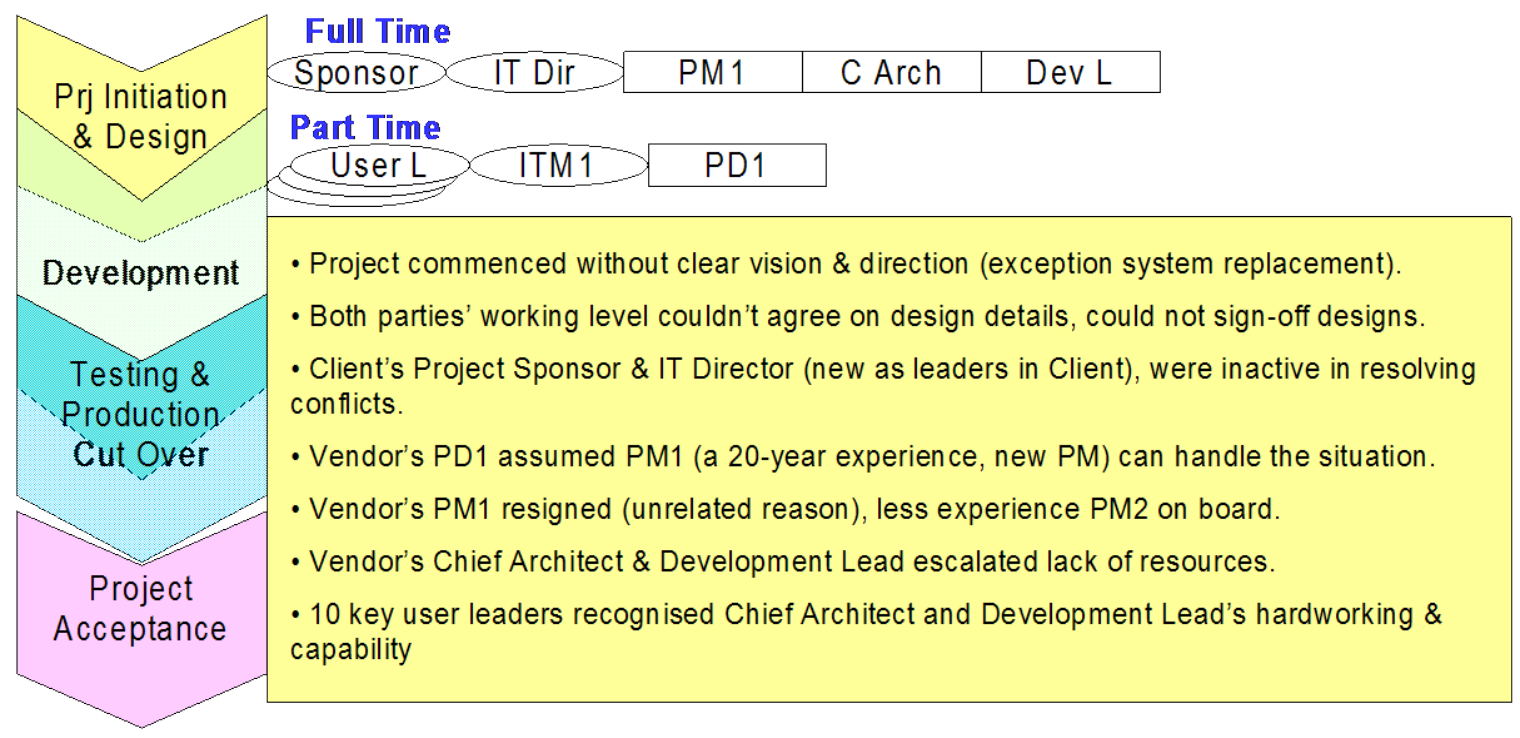

Figure 4 - Stage 1 Context Summary

Figure 4 illustrates key contextual issues at stage 1 of the project.

\section{Leadership team composition:}

o Client side: Project sponsor, IT director, 10 Key user leaders, IT manager (ITM1).

o Vendor side: Part-time project director (PD1), Project manager (PM1), Chief architect, Development lead.

Major events and problems:

The project commenced without any specified vision statement, project charter, firm direction or objectives beyond the aim to replace the existing microfiche system with a web-based system as outlined in a brief business case. The Vendor needed to confirm specific user requirements, define and specify designs so that the Client's ten key user leaders could review and approve the project scope and specific benefits and achieve project sign-off.

The ten key user leaders could not agree with the Vendor chief architect and development lead on design details so the review and sign-off process became extended and protracted. The Client's project sponsor, new to the leadership team, could not contain the conflicting requests and general 'noise' of ten key user leaders who were focussed on their perceptions of the technical detail requirements for the project solution so he adopted a laissez faire leadership style and allowed the Vendor project manager to handle the project scope definition as he saw fit. The Client's IT director, also new to the team, adopted a laissez faire leadership style and did not adopt the role as technical advisor to key user leaders on contract scope nor clarify any technical implications relating to system design requests. Neither could he satisfy the informational nor guidance needs of the IT manager and her IT team. This team maintained a barrage of complaints about what they perceived as unsatisfactory 
technical solutions while not providing constructive solutions to take the project forward. Thus the Client side leadership team generated an atmosphere of distrust about the value of the Vendor's performance.

The Vendor's project director (PD1) had acted in a passive manner and only handled problem escalations from the project manager. This Vendor project manager (PM1), who had over 20 years IT experience, was new to the company and did not personally know his own team members. He worked very hard (by himself) somewhat independently of his team and resigned (for unrelated reasons) before the design signoff was achieved. He was replaced by project manager 2 (PM2) who was a less experience project manager with just over 10 years IT experience and had been working with the Vendor for several years. PM2 came to the project in 'fire-fighting mode' to drive the design sign-off process. The chief architect and development lead were extremely busy and escalated complaints to the project manager about the lack of resources. Nevertheless, their hardworking and capability to demonstrate understanding of the Client's requirements was recognised by key user leaders.

\section{Stage 2: Development stage}

Figure 5 illustrates key contextual issues at stage 2 of the project.

\begin{tabular}{|l|l|l|l|l|} 
Prj Initiation \\
\& Design
\end{tabular}

Figure 5 - Stage 2 Context Summary

Leadership team composition:

o Client side: Director, Operation manager, Project sponsor, IT director, 10 Key user leaders, IT manager (ITM1).

o Vendor side: Managing director (MD1), Project director (PD2), Project manager (PM2), Chief architect, Development manager, Development lead (later taking maternity leave). 
Major events and problems:

A major focus at this stage was achieving an officially design sign-off and complete development of the solution in the shortest timeline to catch up time on time slippages and avoid further delay.

The Vendor replaced PD1 by PD2 who had more time to lead PM2, a relatively less experience project manager. PD2 assessed the situation and made a few decisions. First, she escalated weak sponsorship of both Client's project sponsor and IT director to Client's director and applied pressure to him and the operation manager, who was the head of all ten key user leaders, to be members of the leadership team with the Client's director joining bi-weekly meetings and the operation manager attending weekly project meetings. The Vendor also invited the managing director (MD1), country head of the Vendor, to sit in all meetings with presence of the Client's director. Second, PD2 decided to replace PM2 with a more senior project manager with better political acumen to manage the perceived 'difficult' user leaders. PM3 with almost 20 years IT experience was hired to be the new project manager. Third, PD2 added to the team a tough, taskoriented development manager to coordinate all the internal team activities to free up the chief architect and development lead. They were very accommodating to requests from Client's user leaders and project team members, but this increased work pressures on them to the point of work overload. Fourth, additional resources were added to the project team according to assessment of new development manager. The development lead took maternity leave in the middle of stage 2 and left the project. This stage showed a move from a laissez faire leadership style to a more decisive management by objectives approach illustrated earlier in Figure 1 as closer to active management by exception.

The result of this was that the Client project sponsor and IT director became defensive. The ten key user leaders, under pressure of Client's director and operation manager, expressed their discomfort but finally and unwillingly agreed to sign-off the design, however they retaliated by maintaining their complaints about the Vendor's project team not being able to deliver work on time or to the expected quality.

\section{Stage 3: Testing and production cut over stage}

Figure 6 illustrates key contextual issues at stage 3 of the project. 


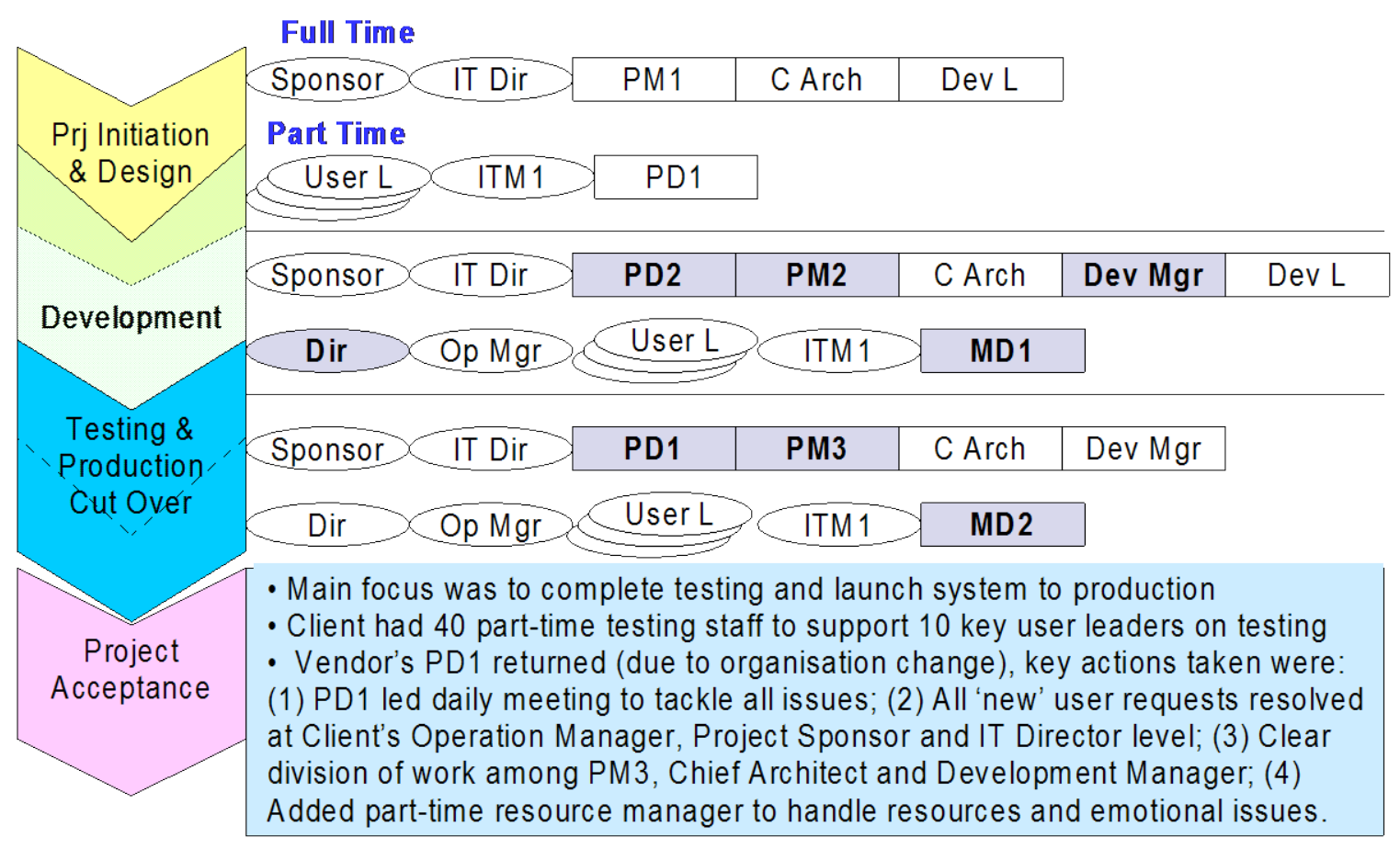

Figure 6 - Stage 3 Context Summary

Leadership team composition:

o Client side: No change

o Vendor side: Managing director (MD2), Project director (PD1), Project manager (PM3), Chief architect, Development manager

Major events and problems:

The major focus at this stage was to complete system testing with a satisfactory result and to launch the system to production. Overall, this stage completed 12 months behind the contractual schedule.

The Client's ten key user leaders engaged a team of 40 part-time users to work in shifts to test the system from 9am to $9 \mathrm{pm}$, Monday through Friday for 9 months ( 3 months was stated in the initial project plan, but was later extended to 9 months). There were plenty of design and quality issues emerging out of this testing process and a large volume of requests for rectification and minor system design changes drained the project resources. The chief architect and many other project team members spent tremendous time serving key user leaders and responding to their demands.

Due to major organisational change of Vendor, MD2 replaced MD1, PD1 returned and replaced PD2 and PM3 was newly placed on board the project team. PD1 implemented several tactic moves to manage the situation.

- First, PD1 held daily meeting to review all issues one by one with PM3, the chief architect and the development manger until solutions were agreed. 
- Second, PD1 and PM3 worked out an agreement with the Client's operation manager, project sponsor and IT director that all new user requests to be implemented by Vendor had to be reviewed at their level and approval obtained before proceeding with these changes. All others would be rejected.

- Third, the division of work of PM3, the development manger and the chief architect were to be:

o PM3 to focus on executing decision of PD1 at contractual level;

- Build relationships with stakeholders and gatekeepers of all requests raised by key user leaders and IT manager;

o The development manager was to be internally focus, only working with the Vendor's project team and executing PD1 decisions; and

o The chief architect was to be advisor of all project team members on all system design issues and technical problems. He also designed solutions to Client requests that had been screened by PM3 and development manager.

- Fourth, PD1 assigned a Vendor resource manager to work part-time on the project to take care of project team emotions and hire additional resources to support testing activities and release much of the project team pressure. New team members would stay on to next stage. Most of the existing team members would be dismissed at end of this stage.

Almost all the Client representatives were defensive and became more demanding. The gap on system design and quality issues gradually narrowed, but it took an additional 6 months.

This stage exhibited an intense form of a constructive transactional leadership style as illustrated in Figure 1. It could be argued that some elements of transformational leadership were creeping in. One explanation is the interesting way that each project team may have perceived their 'family' in this cultural setting. It may reinforce the strong cultural influence upon the leadership style that should have been adopted. There could be an argument made that the two groups Client and Vendor moved away from being seen as opposing 'families or clans' where they each saw the other as an out-group rather than an in-group towards them seeing these two clans merge. At this stage the leadership style seems to recognise (implicitly or explicitly) these cultural conditions and the stakeholder engagement measures may have been an attempt to draw the two 'clans' more closely to being a single 'clan' to create in-group discipline and feelings of unity more in line with the transformational leadership style.

\section{Stage 4: Project acceptance stage}

Figure 7 illustrates key contextual issues at stage 4 of the project. 


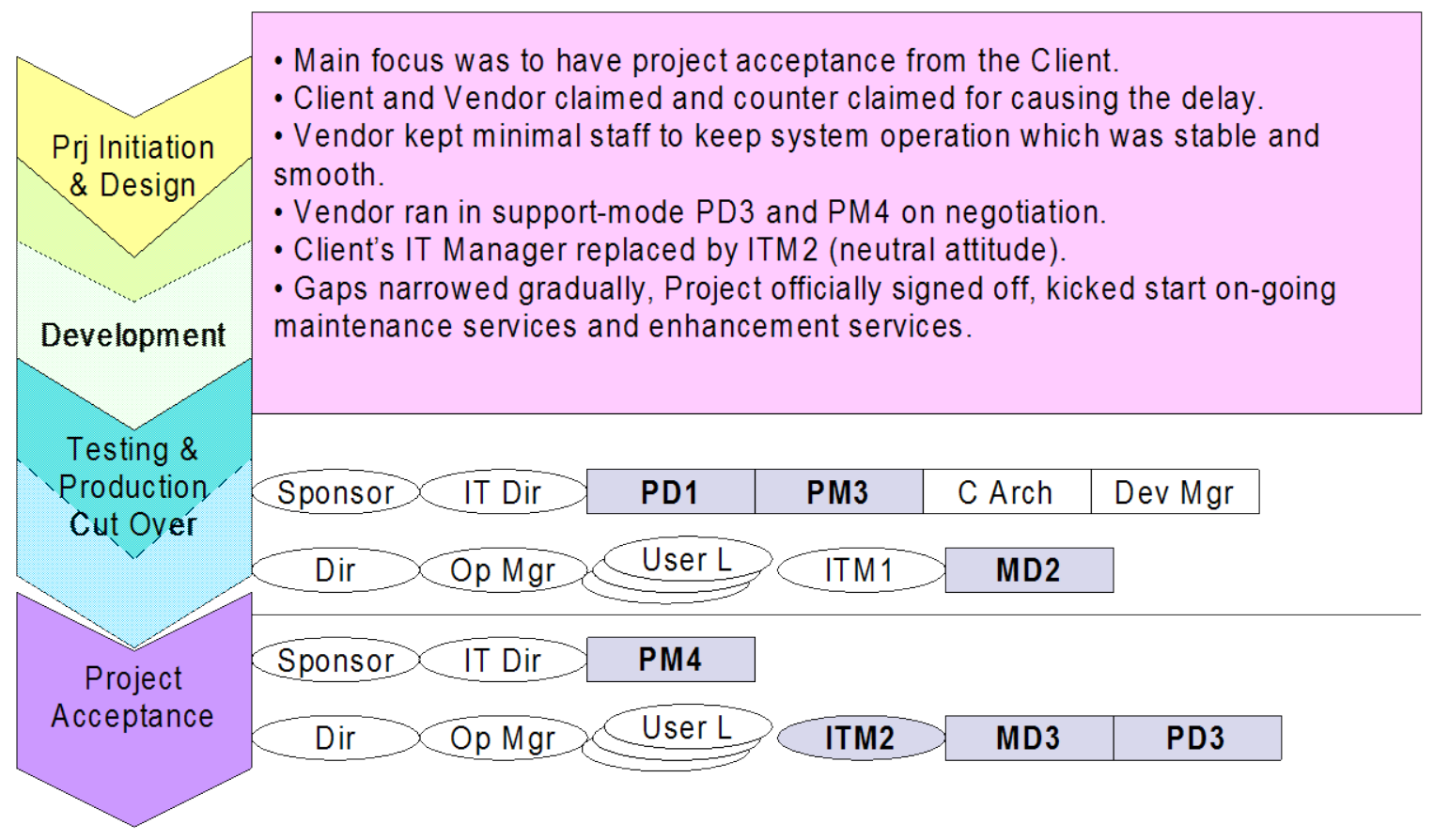

Figure 7 - Stage 4 Context Summary

Leadership team composition:

o Client side: Director, Operation manager, Project sponsor, IT director, 10 Key user leaders, IT manager (ITM2).

o Vendor side: Managing director (MD3), Project director (PD3), Project manager (PM4)

Major events and problems:

The system had its production launch. The major focus at this stage was to have project acceptance from the Client. The project had been struggling all the way through to production. Both the Client and the Vendor had made claim and counter-claim for causing the delay and subsequent losses incurred. It took another 12 months to arrive at a settlement of the project cost and time overrun.

On the Client side, the ITM2 replaced ITM1, and he supported IT director on the project closure contractual paperwork. ITM2 just joined the Client and he had a neutral attitude towards the Vendor. On the Vendor side, MD2 retired and MD3 replaced him. PD3 was the Vendor's supporting manager and was very experienced in project closure, PD1 transited out. PM4 reported to PD3 in the Vendor team and was the project manager of many support projects that followed this project. He replaced PM3 to manage the ongoing maintenance activities. PD3 and PM4 worked patiently with the Client project sponsor, the IT director and ITM2 to negotiate all contractual arguments to arrive at a settlement. PD3 kept a minimal number of staff on the project during the long negotiation process to provide basic services and to keep the system operational. All enhancement requests from the users were kept on hold. 
As this stage the project was officially completed and accepted. The Client then started to pay for on-going maintenance services to the Vendor. The 2 parties also opened a new chapter to initiate the enhancement services discussion. This was recognition of the need of, and desire for, an ongoing relationship between the two sides of the overall project team. There had been a fair degree of mutual accommodation during this process and better understanding of each side's needs and aspirations. This may have been helped by redefining the 'project family' in terms of Confucian culture and therefore the explicit and implied mutual obligations inherent in the guangxi and wulun ${ }^{3}$ concept. This would have demanded a changed leadership style to be appropriate with the transformed notion of the composition of the 'project family'.

\section{Discussion about the Project Case Study Leadership Roles}

We will now attempt to make sense of this case study in terms of the roles and behaviours of the leadership team.

\section{Project Sponsorship}

It would appear that the project management leadership failure moving from Stage One to Stage Four could be explained by the turnover of the Vendor leadership team, which will be reviewed in detailed later in this paper. However, the potential impact of project sponsorship effectiveness that influenced the project's history and perceived failure or success cannot be understated.

The project sponsor is the person or group that provides the financial resources and is the primary risk taker (PMI, 2004) or someone who is responsible for representing the public client and acting within the project as a day-to-day manager of the client's interests (Hall, Holt and Purchase, 2003). Both the project Client sponsor and the IT director (according to the Hall el at. (2003) definition of a public sector project sponsor) could fall under this general definition of sponsor. They represented the public sector organisation in its dealings with the Vendor serving the Client's interest. This is a critical role and one that somebody who occupies the role cannot be assumed to respond "puppet-like" to the prescribed definitions (Helm and Remington, 2005). This senior role also requires political acumen suggesting the need for transformational leadership skills because the sponsor needs to either deliver clarity or vision or to facility this clarity and vision to emerge from project team stakeholders. An inappropriate candidate taking up important roles such as a project sponsor can significantly undermine team morale and focus on the project's vision.

\section{Client Project Sponsorship}

\footnotetext{
${ }^{3}$ Wulun is another Chinese concept related to obligations between people. Wang, X. and Liu, L. (2007). "Cultural barriers to the use of Western project management in Chinese enterprises: Some empirical evidence from Yunnan province." Project Management Journal. 38 (3): 61-73. The Chinese culture stresses family and kinship relationships in doing business. The majority of the five basic kinds of relationships in wulun directly involve family members (1) father-son, (2) husband-wife, and (3) older brother-younger brother but also include the relationships between non family-members considered as honorary "family" members such as (4) ruler-ruled, and (5) friend-friend.
} 
The Client is a public sector organisation selling information to the public and mostly to companies or corporations both locally or for overseas countries. The ICT project was a major initiative to improve public services and also part of an e-government strategy to introduce and support the use of IT. As such this was a high profile project. The Client seconded the full-time project sponsor from his normal duties to liaise with the case study Vendor and oversee project performance. Unfortunately, his position level was not sufficiently senior to fulfil this role. His seniority was lower than the operation manager and in both organisational and culturally, this was insufficient status to fit in with the wulun and influence norms that were expected (Wang and Liu, 2007). Neither did he have knowledge of key operation processes that the operation manager possessed. Worst of all, none of the ten key user leaders were required to report to him, but rather, were required to report to the operation manager. He could hardly be expected to direct the ten key user leaders or effectively support the Client's positions on arguments with the Vendor. In the end, instead of a coordinated position be established, ten separate directions were presented.

The IT director was in no better position to lead with authority than the project sponsor. He was in-sourced from the government IT department to be full-time on the project providing technical and contractual advices to the Client management team on ICT project management issues. The IT manager and IT team did not reported to him so he also could not command respect and exert positional power (authority) over the IT staff.

\section{Other leaders}

The ten key user leaders and the IT manager were part of project management team representing the Client to work with the Vendor on day to day basis. They all had many years experience (varying from a few years to over 20 years) with the Client. Thus, they and not their 'supposed boss' the IT manager, had a wide range of knowledge, connection and personal power sources to effectively influence others and therefore lead the project team (Yukl, 1998). This led to the laissez faire leadership style permeating the project as leaders of critical parts of the project lacked formal authority and this was exacerbated by the Chinese Confucian culture that expected clear authority and power lines.

During the vendor selection stage of the tender process, these leaders had already told the vendor team leaders that they did not trust IT vendors. They had experienced very bad performance on a small ICT project that they believed should have taken 6 months to complete but actually took 18 months to complete. These ten leaders constituted "rogue" stakeholders as described by Bourne and Walker (2004: p234) and were instrumental in inciting conflict during the project. This was evidenced by widespread expressions of distrust and apathy amongst leaders about their dealings with suppliers such as the Vendor. This is similar to that noted by Hall et al. (2003: p500) of other underperforming public sector projects in the UK. These inherent and latent sentiments deteriorated as long as the Vendor team was not considered to be performing as required by the Client's ten key user leaders. 
From stage one to three of the project, they only had trust and confidence in the Vendor's chief architect and development lead (who left the project in the middle of stage two). Trust was exhibited by the three characteristics of trustee - ability, benevolence and integrity identified by Mayer, Davis and Schoorman (1995: p716). However, both the chief architect and the development lead were overwhelmed by the enormous number and scope of requests from these ten leaders. This led to a spiralling degradation cycle of reduced trust in the Vendor that undermined commitment. This undermined the Vendor leadership team's capacity to gain clarity over the project vision, its objectives and many of the operational technical details that needed clarity to be adequately considered.

What was missing from the leadership situation?

Hall et al. (2003: p501) state that in their case study of relational project risks that "The public sector project sponsor's reality was a complex one, juggling the multiple needs of stakeholders and user groups, departmental procedures and practices, pan-government edicts and a sense of public probity and equity with an industry motivated by profit. This was against a backdrop of low levels of trust and fragmentation within that industry, a legacy of adversarial contracts and an 'us-and-them' attitude." The Client's project sponsor and IT director are typical public sector sponsors facing these kinds of challenge.

They had never been effective project sponsors. Helm \& Remington (2005) reflect a general recognition of the vital role played by the project sponsor. Their research has defined a number of themes or attributes of complex projects as necessary for project support at the executive level. These include:

1. Appropriate seniority and power within the organisation;

2. Political knowledge of the organisation and political savvy;

3. Ability and willingness to make connections between project and organisation;

4. Courage and willingness to battle with others in the organisation on behalf of the project;

5. Ability to motivate the team to deliver the vision and provide ad hoc support to the project team;

6. Willingness to partner with the project manager and project team;

7. Excellent communication skills;

8. Personal compatibility with other key players; and

9. Ability and willingness to provide objectivity and challenge the project manager.

The joint force of the Client project sponsor and IT director could hardly be expected to deliver the above attributes in the ICT project. Their limitations on attributes 1 (seniority) and 2 (political knowledge) prevented them from exhibiting other attributes effectively. They were particular weak in juggling the multiple needs of stakeholders and user groups (mainly the ten key user leaders and IT manager), and their 'us-and-them' attitude got worst as the project moved on as described as prevalent by Hall et al. (2003: p501) in their case studies. This is further exacerbated by the Confucian cultural climate which expected those in charge to have defined authority and position power to 
support them and overcome barriers associated with follower expectations (Wang and Liu, 2007).

Suggested explanation of how resolution of problems encountered were attacked Project director (PD2) of Vendor understood how to properly manage the ten key user leaders and IT manager, the sponsors must have power. Bourne and Walker (2005) cite Yukl (1998) to argue that there are three sources of power: (1) Position power, (2) Personal power and (3) Political power. Table 1 below lists the source of power in Client from the project perspective and organisation perspective.

Table 1: Source of power of ICT project and Client organisation

\begin{tabular}{|c|c|c|}
\hline Source of Power & Project perspective & Organisation perspective \\
\hline Position & $\begin{array}{c}\text { Director, } \\
\text { IT director }\end{array}$ & Operation manager \\
\hline Personal & Did not exist & Operation manager \\
\hline Political & Did not exist & Director, \\
& & Operation manager \\
\hline
\end{tabular}

The project sponsor and the IT director had position power within the Client organisation; but they had neither personal nor political power to use with the key user leaders and IT manager. This undermined their authority and this helps explains why the project drifted into different directions dragged by the ten key user leaders and IT manager. The result was lack of a clear vision and clarification of the priority and scope of project objectives that is vital for project success (Christenson and Walker, 2004).

In Stage 2, the first decision made by Vendor project director (PD2) was to respond to the passivity of the Client's director and operation manger by forcing organisational changes in the Vendor leadership group that placed pressure on the Client leadership group to respond and become more accountable.

In Stage 3, the Vendor project director (PD3) further pressured the operation manager to demand accountability in all user request decisions (the second tactic in Stage 3). This made her become fully aware of her user leaders' requests and the impact on the project and Client organisation before she commanded the Vendor to take action. This shored up what could have been perceived as weak previous leadership and firmly established a 'boss' with clear hierarchy that was better aligned to the cultural norms prevailing within the project environment.

In Stage 4, high level hierarchical authority was further enhanced with further changes in appointments to the Vendor's leadership team at the project close. This seems to have been instrumental in generating sufficient confidence to make it possible for the project to merge into a support and service agreement. The political and stakeholder management skills seem also to have been more clearly in evidence and strong hierarchical signals of the status of the leadership team further supported cultural expectations. 


\section{Discussion about the Project Case Study Project Leadership Styles}

The Vendor experienced extensive project leader attrition throughout the project life cycle. At each of the four stages, there was a different mix of leaders, and with that different leadership styles. Managing directors in this project only played a figure-head role, they did not exert direct influence on the project management strategies but strong MD leadership action did deliver authority to the Vendor team that built confidence. The actual leadership team at each stage was the twinning of project director and project manager, except in Stage 3 where the development manager was part of the project management leadership team. The project management leadership teams in the 4 stages are respectively: PD1+PM1, PD2+PM2, PD1+PM3 (external project manager) + development manager (internal project manager) and PD3+PM4.

Much of the contemporary literature (see for example Crawford, Costello, Pollack and Bentley, 2003; Pollack, 2007) shares the view expressed by Bourne and Walker (2004: p226) - "...the PM role (has) an additional focus on the so-called "soft" aspects ... is particularly relevant when considering non-traditional, non-construction projects delivering "intangible" results, such as those in the sphere of ICT or business process change". This ICT project is a typical case that demonstrates the essence of "soft" aspects. In the different school of thoughts on leadership theories, the behavioural or style school assumes that effective leaders adopt certain styles or behaviours, and the effective leaders can be made (Turner and Müller, 2005). In behavioural school, Dainty, Cheng \& Moore (2005) defined 12 behavioural competencies with some being highly relevant to this ICT project. Under the Visionary or Charismatic leadership school, Bass' transactional and transformational leadership are often cited (Keegan and Den Hartog, 2004; Turner and Müller, 2005). In this project both leadership styles have been observed. Last but not least, the three types of competence : intellectual (IQ), Managerial skill (MQ) and Emotional (EQ) discussed by Dulewicz and Higgs (2000), are also worthwhile mentioning in this project as the Vendor project team worked under very high pressure in the first three project stages, but the staff turnover rate (churn) was not particularly high. We argue that improved 'soft' leadership must have happened to prevented staff attrition.

\section{Behavioural Competencies}

Dainty, Cheng \& Moore (2005) defined 12 behavioural competencies that differentiated superior and average performing managers, group into seven cluster types. Four cluster types are particular relevant to this ICT project. They are: human serviceoriented competencies (customer service orientation); Impact and influence-based competencies (impact and influence, organisational awareness); achievement and action oriented competencies (task focus, high initiative, and information seeking to perform at an excellent level); and managerial competencies (teamwork and cooperation, team leadership, directiveness).

In stage 1, PD1+PM1 were weak in all 4 aspects. PD1 had been inactive as he assumed PM1 was a well-experienced project manager should have adequate competencies to manage the project. Unfortunately, PM1 had just joined the Vendor for a few months, his commitment to the company and his knowledge of his team was 
limited. The chief architect and development lead had pleaded to PM1 for resources but was constrained in gaining these by the project budget and he hesitated to add required resources at the very beginning of the project. PM1 was only on the project for a short period of time, he had not demonstrated other relevant competencies.

In Stage 2, PD2+PM2 were strong on both 'human service-oriented and impact' and 'influence-based' competencies. After understanding the political situation, PD2 enforced Client's sponsorship improvement. At this stage, this group of Vendor project leaders still tried to be accommodative and accommodate the Client's requests as much as possible. In terms of their 'Managerial competencies', this group's strength was teamwork and cooperation. They tried to align the Client side's key user leaders and Vendor's project team members to work closely together as a team, though with not a great deal of success.

In Stage 3, the situation did not allow the project to further slip. PD1 understood that PM3 was similar to PM1, as he was new to the Vendor team and the project so it was impossible for him to be fully accountable for such complex and unstable project being delivered at full speed. He complemented PM3's shortcomings with the strength of the development manager who was directive and demanding in approach, he ensured all project team members comply with PD1's wishes. 'Human service-oriented' competencies and 'impact and influence-based' competencies were less demonstrated in Stage 3 as compared to Stage 2. PD1 and the development manager exhibited more 'achievement orientation' competencies.

In Stage 4, PD3+PM4 put more focus on 'human service-oriented' competencies and 'impact and influence-based' competencies. They understood that after the project was closed, new support, maintenance and enhancement services contracts would be required. With most of the project team members dismissed in this stage, they slowly introduced new team members during that period.

Transactional and transformational leadership

Keegan and Den Hartog (2004: p610) cite Bass (1985) and Burns (1978) that:

"Transformational leadership is often contrasted with transactional leadership. Transactional leadership is based on (a series of) exchanges between leader and follower. Followers receive certain valued outcomes (e.g. wages, prestige) when they act according to the leader's wishes.... Transformational leadership goes beyond the cost-benefit exchange of transactional leadership by motivating and inspiring followers to perform beyond expectations ...."

In this ICT project, during almost all stages, the Vendor's project leadership team used a transactional leadership style to work with the Client and vice versa. With the widespread feeling of distrust and apathy amongst the Client's leaders, most interchanges among Vendor and Client leaders were based on every encounter being a negotiation based purely on a cost-benefit exchange. 
However, at the non-leader level, Vendor leaders exhibited a transformational leadership style to work as facilitating partners with the project team members and reduce feelings of frustrations in working on the project. Life was particular tough in Stage 3. Users were working in shifts, but not the Vendor team. Limited knowledge and resources forced to team to work long hours for many months. Although PD1+PM3+ the development manager imposed directives to drive these activities, these actually took into account team workloads and were seen as good role models. These 3 leaders protected and shielded the project team members from access by the Client and provided them with peace and quiet to focus on their own work. They also strove to motivate the team so this indicates use of some of the transformational leadership 4l's (Avolio, 1996) as indicated in Figure 1, particularly gaining trust and being a role model in the first ' $l$ '.

Intellectual (IQ), Managerial skill (MQ) and Emotional (EQ)

Dulewicz \& Higgs (2000) argue that IQ, EQ, MQ should be applied in unison when leading teams. Turner and Müller (2005: p54) quotes Dulewicz \& Huggs work, says "...emotional competence (EQ) accounts for $36 \%$. Emotional competence is ... the most significant, but the other two (IQ and MQ) are important". This shows EQ is most important scale for one to be successful.

In this project, it is not meaningful to compare the IQ, EQ and MQ of leaders or find out who has higher EQ and therefore more successful than others. However, PD1 in Stage 3 exercised the fourth tactic by adding the resource manager to the picture. The resource manager took care of project team emotions and hired additional resources to support testing activities and release pressure of project team. This is an important action to provide emotional and practical support to the highly stressful and tiring Vendor's project team. This action gave "Hope, Trust and Positive Emotions" advocated by Avolio et al. (2004: p808) as being indicative of authentic leadership to enhance the engagement, motivation, commitment, satisfaction and involvement required of the project team. This may not demonstrate PD1 has having high EQ, but he did care enough for the emotions of the project team members and tried to help them to utilise their emotional intelligence better.

\section{Project Team Interactions}

In the above discussion, a unique member in the project leadership team has not yet been mentioned; he was the Vendor's chief architect. He was the only leader who survived through Stages 1 to 3 on the Vendor side. He also worked on a part-time basis to provide support on preparing and presenting the contractual arguments to PD3 and PM4 in Stage 4.

This person has worked for the Vendor for many years, and is accustomed to taking up the role of chief architect in projects. This ICT project was not a particularly complex nor large project for him. However, pressure-wise, this was arguably the toughest for him as nobody in the project knew all the arguments to respond to the many difficult moments throughout the project's duration. The Client only trusted him on all issues after the development lead left the project. The chief architect had been in a unique position. The 
Key Client user leaders had trust in him as did the Vendor project directors, project managers and the Vendor project team members. Nevertheless, why did the chief architect not quit rather than endure high levels of stress and pressure on this project?

The chief architect and the development lead exhibited three trustee characteristicsability, benevolence and integrity (Mayer et al., 1995). This suggests motivation was evident in what Avolio et al. (2004: p806) define as a key leader characteristic, "authentic leaders... are more interested in empowering the people they lead to make a difference, and are as guided by the qualities of the heart, passion, and compassion as they are by qualities of the mind." The chief architect has always been helpful and willing to help others to succeed. People enjoyed working with him or work for him.

Throughout the project, he was the project leader who always worked the longest hour and stayed with project team in all tough events. He exhibited strong commitment to the project. He might be committed to Vendor, but most likely his commitment also worked on alternative targets - profession, customer, and personal career as suggested by Meyer and Herscovitch (2001).

The way that the chief architect on the Vendor side team became a trusted leader and role model of the Vendor project team was through his actions. He demonstrates the seven principles of effective teamwork offered by De Vries (1999), who researched high performance teams and identified seven effective teamwork principles:

1. Members respect and trust each other;

2. Members protect and support each other;

3. Members engage in open dialogue and communication;

4. Members share a strong common goal;

5. Members have strong shared values and beliefs;

6. Members subordinate their own objectives to those of the team; and

7. Members subscribe to "distributed" leadership."

The Vendor's project Stage 2/3 team understood they could only survive by working together as a team. They shared a common goal - have the system production launch the soonest. Together, they created the legend of a stable project team. Majority of team members worked till the project production launch.

The Client's project team also interacted as a committed team with common goal, and they had trust and respect to their leader - the operation manager. This helped the two 'clans' coalesce because the operation manager had managed to focus the ten key user leaders to understand a common project goal that also was shared by the Vendor 'clan'.

\section{Conclusion}

There are numerous lessons that can be learned from this project. It was clear that the Client's senior managers were unaware of the vital importance of neither selecting the right project sponsors nor providing the support to make them effective. The poisonous ingredient of distrust was carried forward from previous bad ICT project delivered experiences to this project, even though it involved an entirely different IT company. If 
such pre-empted emotion is not removed, then the Client would find it extremely difficult to experience a successful ICT project by being influenced by negative 'baggage' that can undermine perceptions of trust and commitment on any future projects.

The Vendor's assumption that a well-experienced project manager, like PM1, should be able to manage this ICT project was proved incorrect. Many of the project manager competencies identified by Dainty Cheng \& Moore (2005) (e.g. organisational awareness, teamwork and cooperation) cannot automatically be carried forward, purely propelled by personal experience, from one project (or company) to the next. However, project leaders can better prepare themselves for the challenges of each new project by spending time in the organisation and project and working on understanding the maturity levels, organisational culture and influencing national cultural drivers of behaviour. Project managers need to exhibit skills beyond technical competence (Crawford, Morris, Thomas and Winter, 2006), they need to be able to be politically and culturally aware by deploying the skills project that Bourne and Walker (2004) refer to as tapping into the power lines, or understanding political/cultural constrains and drivers.

Frequent change in project directors and project managers in the Vendor's teams over this project was both unhealthy and damaging to the already distrusting relationship that the Client was predisposed to. Initial Vendor and Client team leaders also lacked sufficient hierarchical authority to be perceived as credible leaders given the prevailing national culture of the project context. Nevertheless, different project management styles exercised at different stages seem to follow an appropriate trajectory in Stage 2 to 4 . However, one may argue that if Stage 1 had been established using a better leadership foundation, then the drastic tactics imposed in Stage 2 and 3 might not have been necessary.

Stage 1 began with a lack of an authoritative leadership structure on both Vendor and Client sides and this led to a poor vision being explicated regarding what was expected to be the clear benefit of this project that in turn led to poor clarity in objectives which in turn led to an ad hoc and laissez faire approach to scope definition, performance monitoring and control and poor motivation and little evidence of affective commitment being engendered. This made leading difficult. Further, the inadequacies highlighted at Stage 1 presented a cultural clash in leadership style. All these paradoxes forced a drastic re-framing of approaches to leadership style that evolved in Stage 2 through Stage 4 which became more actively transactional that may have suited the maturity level of team embers at that stage. The way that the Vendor's project team performed under pressure in Stages 2 to Stage 4 demonstrated how a team can survive in an unstable, tough environment and we say that this may have been influenced by the transformational leadership style of the Vendor's chief architect. We do not need every project to be so tough, or every team to have a heroic chief architect or other pivotal team member who needs to work excessively long hours.

Organisations need to learn how to be an effective team on projects and to achieve effective teamwork. This requires leaders to establish the conditions that best offer a prospect of highly performing teams. This in turn requires an organisational structure 
that establishes and permits a leadership style that is appropriate to the project circumstances. The findings reported here suggest that organisational maturity and national culture play a key role in providing the foundations for leading projects using a style that maximises trust, affective commitment and cooperation between Client and Vendor teams.

The Hall, Holt \& Purchase (2003: p501) study suggests that relational partnering-type approaches are "vital in encouraging project level co-operation between the various organisations involved in the project...(project sponsors) develop partnering type relationships to prevent potentially project damaging antagonisms developing." Further, their research identified a correlation between the strength of these relationships and the success of the project. Whether 'partnering' is the solution to rescue a badly performing project like this ICT project is unknown. However, if 'us-and-them' attitudes can be eliminated, then both Client and Vendor team leaders can experience better dialogue and mutual understanding to identify issues prior all the 'antagonisms' being accumulated to a point of no return, then at least problems and issues have a chance to be resolved as a team. This can be realised, at least under the cultural environment of this case study, by expanding the Vendor project team interactions into the 'us' team.

\section{References}

Avolio, B. (1996). What's All the Karping About Down Under? Leadership research and Practice. W. Parry K. W. Ed. South Melbourne. Pitman Publishing: 3-15.

Avolio, B. J., Gardner, W. L., Walumbwa, F. L. and May, D. R. (2004). “Unlocking the Mask: A look at the Process by which Authentic Leaders Impact Follower Attitudes and Behaviors.” Leadership Quarterly. 15: 801-823.

Avolio, B. J., Waldman, D. A. and Yammarino, F. J. (1991). "Leading in the 1990's: The Four I's of Transformational Leadership.” Journal of European Industrial Training. 15 (4): 11.

Bass, B. M. (1985). Leadership and Performance Beyond Expectations, ～， Free Press, New York.

Bourne, L. (2005). Project Relationship Management and the Stakeholder Circle. Doctor of Project Management, Graduate School of Business,. Melbourne, RMIT University.

Bourne, L. and Walker, D. H. T. (2004). “Advancing Project Management in Learning Organizations.” The Learning Organization, MCB University Press. 11 (3): 226-243.

Bourne, L. and Walker, D. H. T. (2005). "Visualising and Mapping Stakeholder Influence.” Management Decision. 43 (5): 649-660.

Burns, J. M. (1978). Leadership.New York Harper \& Row.

Cartwright, D. and Zander, A. (1960). Group dynamics : research and theory.2nd ed.London Tavistock.

Castka, P., Bamber, C. F., Sharp, F. M. and Belohoubek, P. (2001). “Factors Affecting Successful Implementation of High Performance Teams.” Team Performance Management. 7 (7/8): 123-134.

Christenson, D. and Walker, D. H. T. (2004). "Understanding the Role of "Vision" in Project Success.” Project Management Journal. 35 (3): 39-52.

Cicmil, S. (1999). "Implementing organizational change projects: impediments and gaps.” Strategic Change. 8 (2): 119-129. 
Cicmil, S. (2006). “UNDERSTANDING PROJECT MANAGEMENT PRACTICE THROUGH INTERPRETATIVE AND CRITICAL RESEARCH PERSPECTIVES.” Project Management Journal. 37 (2): 27-37.

Cicmil, S. and Hodgson, D. (2005). "Knowledge, action, and reflection in management education - the case of project management.” BBS Teaching and Research Review,. September (7): 28pp.

Cooke-Davies, T. (2002). “The "Real" Success Factors on Projects.” International Journal of Project Management. 20 (3): 185-190.

Crawford, L. and Cooke-Davies, T. J. (2006). Project Governance - The Role and Capabilities of the Executive Sponsor. PMOZ - Achieving Excellence, Melbourne, Australia, 8-11 August, PMI - Melbourne Chapter: 1-11 CD-ROM paper.

Crawford, L., Costello, K., Pollack, J. and Bentley, L. (2003). "Managing soft change projects in the public sector.” International Journal of Project Management. 21 (6): 443-448.

Crawford, L., Morris, P., Thomas, J. and Winter, M. (2006). "Practitioner development: From trained technicians to reflective practitioners.” International Journal of Project Management. 24 (8): 722-733.

Dainty, A. R., J., Cheng, M.-I. and Moore, D. (2005). “A Comparison of the Behavioral Competencies of Client-Focused and Production-Focused Project Managers in the Construction Sector.” Project Management Journal. 36 (2): 39-49.

De Vries, M. F. R. K. (1999). “High-Performance Teams: Lessons from the Pygmies.” Organizational Dynamics. 27 (3): 66.

de Wit, A. (1988). “Measurement of project success.” International Journal of Project Management. 6 (3): 164-170.

Dulewicz, V. and Higgs, M. (2000). "Emotional Intelligence: A Review and Evaluation Study.” Journal of Managerial Psychology. 15 (4): 341.

Englund, R. L. and Bucero, A. (2006). Project Sponsorship : Achieving Management Commitment for Project Success San Francisco Jossey-Bass.

Green, S. (2006). The management of projects in the construction industry: context, discourse and self-identity. Making Projects Critical. Hodgson D. and S. Cicmil. Ed. Basingstoke, UK. Palgrave MacMillan: 232-251.

Hall, M., Holt, R. and Purchase, D. (2003). "Project sponsors under New Public Management: lessons from the frontline.” International Journal of Project Management. 21 (7): 495502.

Helm, J. and Remington, K. (2005). "Effective Project Sponsorship an Evaluation of the Role of the Executive Sponsor in Complex Infrastructure Projects by Senior Project Managers.” Project Management Journal. 36 (3): 51-61.

Hersey, P., Blanchard, K. and Johnson, D. E. (1996). Management of Organizational Behaviour.7th.London Prentice Hall International.

Hobday, M. (1998). "Product Complexity, Innovation and Industrial Organisation.” Research Policy. 26 (6): 689-710.

Hobday, M., Rush, H. and Tidd, J. (2000). “Innovation in complex products and system.” Research Policy. 29 (7-8): 793-804.

Hofstede, G. (1991). Culture and Organizations: Software of the Mind.New York McGrawHill. 
Hofstede, G., Neuijen, B., Ohayv, D. D. and Sanders, G. (1990). "Measuring Organizational Cultures: A Qualitative and Quantitative Study across Twenty Cases.” Administrative Science Quarterly. 35 (2): 286-316.

Hofstede, G. H. (1980). Culture's Consequences: International Differences in Work-Related Values.Beverly Hills Sage.

Ivory, C. J., Alderman, N., Ian, M. and Vaughan, R. (2006). Sense-making as a process within complex projects. Making Projects Critical. Hodgson D. and S. Cicmil. Ed. Basingstoke, UK. Palgrave MacMillan: 316-334.

Keegan, A. E. and Den Hartog, D. N. (2004). “Transformational Leadership in a Project-Based Environment: A Comparative Study of the Leadership Styles of Project Managers and Line Managers.” International Journal of Project Management. 22 (8): 609-617.

Kendra, K. and Taplan, L. J. (2004). “Project Success: A Cultural Framework.” Project Management Journal. 35 (1): 30-46.

Kloppenborg, T. J., Tesch, D., Manolis, C. and Heitkamp, M. (2006). “AN EMPIRICAL INVESTIGATION OF THE SPONSOR'S ROLE IN PROJECT INITIATION.” Project Management Journal. 37 (3): 16-25.

Kotter, J. P. (1998). What Leaders Really Do. Harvard Business Review on Leadership. Review H. B. Ed. Boston, MA. Harvard Business School Publishing: 37-60.

Lennie, J. (2006). "Increasing the rigour and trustworthiness of participatory evaluations: learnings from the field.” Evaluation Journal of Australisia. 6 (1): 27-35.

Lundin, R. A. and Söderholm, A. (1995). "A theory of the temporary organization.” Scandinavian Journal of Management. 11 (4): 437-455.

Lynn, G. S. and Akgün, A. E. (2001). "Project Visioning: Its components and impact on new product success.” The Journal of Product Innovation Management. 18 (6): 374-387.

Mayer, R. C., Davis, J. H. and Schoorman, F. D. (1995). “An Integrated Model of Organizational Trust.” Academy of Management Review. 20 (3): 709-735.

McIntyre, J. (2002). "An adapted version of a community of practice approach to evaluation owned by indigenous stakeholders.” Evaluation Journal of Australisia. 2 (2): 57-59.

Meyer, J. P. and Allen, N. J. (1991). “A Three-Component Conceptualization of Organizational Commitment.” Human Resource Management Review. 1 (1): 61-89.

Meyer, J. P. and Herscovitch, L. (2001). "Commitment in the Workplace: Toward a General Model.” Human Resource Management Review. 11 (3): 299-326.

Morris, P. W. G. and Hough, G. H. (1993). The Anatomy of Major Projects - A Study of the Reality of Project Management.London Wiley.

Park, S. H. and Luo, Y. (2001). "Guanxi and organizational dynamics: organizational networking in Chinese firms.” Strategic Management Journal. 22 (5): 455-477.

Pettigrew, A. M. (1997). "What is a processual analysis?” Scandinavian Journal of Management. 13 (4): 337-348.

PMI (2004). A Guide to the Project Management Body of Knowledge.3rd Edition.Sylva, NC, USA Project Management Institute.

Pollack, J. (2007). “The changing paradigms of project management.” International Journal of Project Management. 25 (3): 266-274.

Schön, D. A. (1983). The Reflective Practitioner - How Professionals Think in Action.Aldershot, UK BasiAshgate ARENA.

Sense, A. J. (2005). Cultivating Situational Learning Within Project Management Practice. PhD, Macquarie Graduate Shool of Management. Sydney, Macquarie University. 
Sense, A. J. and Antoni, M. (2003). “Exploring the Politics of Project Learning.” International Journal of Project Management. 21 (7): 487-494.

Standish (2003). Latest Standish Group CHAOS Report Shows Project Success Rates Have Improved by 50\%, http://www.standishgroup.com/press/article.php?id=2, March 25

Trompenaars, F. (1993). Riding the Waves of Culture: Understanding Cultural Diversity in Business.London Economics Books.

Trompenaars, F. and Hampden-Turner, C. (2004). Managing people : across cultures.Chichester, England Capstone.

Tuckman, B. W. and Jensen, M. A. (1977). "Stages of Small Group Development Revisited.” Group and Organizational Studies. 2 (4): 419-427.

Turner, J. R. and Müller, R. (2003). "On the Nature of the Project as a Temporary Organization.” International Journal of Project Management. 21 (3): 1-8.

Turner, J. R. and Müller, R. (2005). “The Project Manager's Leadership Style as a Success Factor on Projects: A Literature Review.” Project Management Journal. 36 (2): 49-61.

Wang, X. and Liu, L. (2007). "Cultural barriers to the use of Western project management in Chinese enterprises: Some empirical evidence from Yunnan province.” Project Management Journal. 38 (3): 61-73.

Winter, M. and Thomas, J. (2004). Understanding the Lived Experience of Managing project: The need for More Emphasis on the Practice of Managing. Innovations - Project Management Research 2004. Sleven D. P., D. I. Cleland and J. K. Pinto. Ed. Newtown Square, PA. Project management Institiute: 419-436.

Yukl (1998). Leadership in Organisations.4th.Sydney Prentice-Hall. 